\title{
Tracing atmospheric nitrate in groundwater using triple oxygen isotopes: evaluation based on bottled drinking water
}

\author{
F. Nakagawa ${ }^{1}$, A. Suzuki ${ }^{1}$, S. Daita ${ }^{1}$, T. Ohyama ${ }^{2}$, D. D. Komatsu ${ }^{2}$, and U. Tsunogai ${ }^{2}$ \\ ${ }^{1}$ Earth and Planetary System Science, Faculty of Science, Hokkaido University, N10 W8, Kita-ku, Sapporo, 060-0810, Japan \\ ${ }^{2}$ Graduate School of Environmental Studies, Nagoya University, Furo-cho, Chikusa-ku, Nagoya 464-8601, Japan
}

Correspondence to: U. Tsunogai (urumu@nagoya-u.jp)

Received: 26 October 2012 - Published in Biogeosciences Discuss.: 20 November 2012

Revised: 13 April 2013 - Accepted: 29 April 2013 - Published: 3 June 2013

\begin{abstract}
The stable isotopic compositions of nitrate dissolved in 49 brands of bottled drinking water collected worldwide were measured, to trace the fate of atmospheric nitrate $\left(\mathrm{NO}_{3 \mathrm{~atm}}^{-}\right)$that had been deposited into subaerial ecosystems, using the ${ }^{17} \mathrm{O}$ anomalies $\left(\Delta^{17} \mathrm{O}\right)$ of nitrate as tracers. The use of bottled water enables collection of groundwater recharged at natural, background watersheds. The nitrate in groundwater had small $\Delta^{17} \mathrm{O}$ values ranging from $-0.2 \%$ o to $+4.5 \%$ o $(n=49)$. The average $\Delta^{17} \mathrm{O}$ value and average mixing ratio of atmospheric nitrate to total nitrate in the groundwater samples were estimated to be $0.8 \%$ and $3.1 \%$, respectively. These findings indicated that the majority of atmospheric nitrate had undergone biological processing before being exported from the surface ecosystem to the groundwater. Moreover, the concentrations of atmospheric nitrate were estimated to range from less than $0.1 \mu \mathrm{molL} \mathrm{L}^{-1}$ to $8.5 \mu \mathrm{molL} \mathrm{L}^{-1}$, with higher $\mathrm{NO}_{3 \mathrm{~atm}}^{-}$concentrations being obtained for those recharged in rocky, arid or elevated areas with little vegetation and lower $\mathrm{NO}_{3 \mathrm{~atm}}^{-}$concentrations being obtained for those recharged in forested areas with high levels of vegetation. Additionally, many of the $\mathrm{NO}_{3 \mathrm{~atm}}^{-}$-depleted samples were characterized by elevated $\delta^{15} \mathrm{~N}$ values of more than $+10 \%$ o. Uptake by plants and/or microbes in forested soils subsequent to deposition and the progress of denitrification within groundwater likely plays a significant role in the removal of $\mathrm{NO}_{3}^{-}$atm .
\end{abstract}

\section{Introduction}

Anthropogenic activities have increased emissions of fixed nitrogen from land to the atmosphere. Indeed, the amount of these emissions has almost doubled globally, with much greater increases being observed in some regions, and this fixed-nitrogen flux is expected to double again by 2030 (Galloway et al., 2008). Excess fixed-nitrogen input is linked to various environmental problems, including forest decline (e.g., Fenn et al., 1998), degradation of groundwater quality (e.g., Murdoch and Stoddard, 1992; Williams et al., 1996), eutrophication of the hydrosphere (e.g., Paerl, 1997; Duce et al., 2008), and shifts in biodiversity (e.g., Tilman et al., 1996).

Previous detailed studies of forested catchments have offered considerable insight into the link between atmospheric nitrate deposition and nitrate discharge to streams (Grennfelt and Hultberg, 1986; Williams et al., 1996; Tietema et al., 1998; Durka et al., 1994). Although water chemistry has been routinely measured through many programs on regional to international scales, our understanding of the mechanisms that regulate the discharge of atmospheric deposition from surface ecosystems is still limited. This is because the fate of atmospheric nitrate deposited onto the subaerial ecosystem is determined through the complicated interplay of several processes that include (1) dilution through nitrification, (2) uptake by plants or microbes, and (3) decomposition through denitrification.

In a previous study, we determined the ${ }^{17} \mathrm{O}$ anomalies of nitrate in groundwater recharged on the island of Rishiri, Japan to trace the fate of atmospheric nitrate $\left(\mathrm{NO}_{3 \mathrm{~atm}}^{-}\right)$ that had been deposited onto and passed through the island 
ecosystem. In that study, we estimated the average mixing ratio of atmospheric nitrate to total nitrate in the groundwater to be $7 \%$ (Tsunogai et al., 2010). Based on this mixing ratio, we estimated that direct drainage accounts for $10.5 \pm 5.2 \%$ of atmospheric nitrate that has been deposited onto the island, and that the residual portion has undergone biological processing before being exported from the island ecosystem at the groundwater recharge zones.

Anomalies in ${ }^{17} \mathrm{O}$ can be quantified using the $\Delta^{17} \mathrm{O}$ signature, which is defined by the following equation (Miller, 2002; Kaiser et al., 2007):

$\Delta^{17} \mathrm{O}=\frac{1+\delta^{17} \mathrm{O}}{\left(1+\delta^{18} \mathrm{O}\right)^{\beta}}-1$,

where $\beta$ is 0.5247 (Miller, 2002; Kaiser et al., 2007), $\delta^{18} \mathrm{O}=R_{\text {sample }} / R_{\text {standard }}-1$ and $R$ is the ${ }^{18} \mathrm{O} /{ }^{16} \mathrm{O}$ ratio (or the ${ }^{17} \mathrm{O} /{ }^{16} \mathrm{O}$ ratio in the case of $\delta^{17} \mathrm{O}$ or the ${ }^{15} \mathrm{~N} /{ }^{14} \mathrm{~N}$ ratio in the case of $\delta^{15} \mathrm{~N}$ ) of the sample and each international standard. By using the $\Delta^{17} \mathrm{O}$ values of nitrate, we can distinguish $\mathrm{NO}_{3 \text { atm }}^{-}\left(\Delta^{17} \mathrm{O}>0\right)$ from the remineralized nitrate $\left(\mathrm{NO}_{3 \mathrm{re}}^{-}\right)$ $\left(\Delta^{17} \mathrm{O}=0\right)$. Additionally, $\Delta^{17} \mathrm{O}$ is stable during usual massdependent isotope fractionation processes; therefore, we can use $\Delta^{17} \mathrm{O}$ as a conserved tracer of $\mathrm{NO}_{3}^{-}$atm and trace $\mathrm{NO}_{3 \text { atm }}^{-}$ irrespective of partial removal through denitrification and/or uptake reactions that occur after deposition. Previous studies of the $\Delta^{17} \mathrm{O}$ values of nitrate in freshwater environments demonstrated that $\Delta^{17} \mathrm{O}$ values can serve as robust tracers of the fate of $\mathrm{NO}_{3 \text { atm }}^{-}$deposited onto a surface ecosystem without using artificial tracers (Michalski et al., 2004; Tsunogai et al., 2010, 2011; Dejwakh et al., 2012). Measuring the $\Delta^{17} \mathrm{O}$ values of nitrate for water eluted from various watersheds can increase our understanding of fixed-nitrogen processing and fixed-nitrogen retention efficiencies for surface natural ecosystems that are subjected to atmospheric fixed-nitrogen deposition.

In this study, we determined the $\Delta^{17} \mathrm{O}$ values of nitrate in various types of bottled drinking water collected from different markets by applying those representing groundwater recharged at natural watersheds worldwide (Tsunogai and Wakita, 1995, 1996). Using bottled drinking water for the samples reduced the time, labor, and costs relative to those that would be required for direct groundwater sampling. Moreover, the use of bottled water enables collection of groundwater recharged at natural background watersheds where there have been few artificial alternations and little contamination. The use of bottled water also prevents samples of groundwater systems recharged in declining or damaged forested watersheds as well as anoxic nitrate-exhausted groundwater.

Using the $\Delta^{17} \mathrm{O}$ tracer, we quantified the fraction of $\mathrm{NO}_{3 \mathrm{~atm}}^{-}$within the total nitrate output in groundwater to gain insight into the processes controlling the fate and transport of $\mathrm{NO}_{3 \mathrm{~atm}}^{-}$deposited onto natural subaerial ecosystems. The quantified $\mathrm{NO}_{3 \text { atm }}^{-}$output will be useful in future studies as a basic background data set for evaluation of the amounts of $\mathrm{NO}_{3}^{-}$atm eluted into groundwater from subaerial ecosystems in general, including the same watersheds under elevated $\mathrm{NO}_{3 \mathrm{~atm}}^{-}$input in the future.

In addition to clarifying the fate of atmospheric nitrate, this study was also conducted to gain insight into the processes controlling the total nitrate concentrations in groundwater. Because nitrate enrichment of drinking water causes infantile methemoglobinemia, major factors controlling nitrate concentrations must be clarified for each groundwater system. The determination of stable isotopic compositions of nitrate in groundwater will provide insight into the processes controlling the nitrate concentrations in natural groundwater, especially for the contribution of atmospheric nitrate into groundwater.

\section{Experimental section}

\subsection{Sample description}

We collected as many bottled drinking water samples as possible from supermarkets in Sapporo and Nagoya, Japan. Because of increasing numbers of people becoming healthconscious in Japan, it is possible to obtain a wide variety of bottled drinking water from supermarkets. In addition to samples collected from Japanese supermarkets, we asked acquaintances abroad to send bottled drinking water to Japan.

We collected a total of 48 brands of bottled drinking water (Nos. 2 to 49 in Table 1) that had been sealed in either polyethylene terephthalate bottles or glass bottles and distributed on the market as drinking water. About $70 \%$ of the samples collected were from abroad (Fig. 1). The longest storage period between bottling and analysis was less than a year. In addition to the water being collected in this study, a brand of bottled drinking water collected and analyzed in Tsunogai et al. (2010) (Rishiri water) has been included in our discussions (No. 1 in Table 1).

The methods of sterilization are presented in the table as well. Because the EU directive for bottled mineral water prohibits sterilization, most of the samples from Europe were non-sterile. Conversely, most samples from Japan were sterilized by either (1) microfiltration $(0.2 \mu \mathrm{m})$, and/or (2) heating to $130{ }^{\circ} \mathrm{C}$ for at least $2 \mathrm{~s}$; therefore, both concentrations and stable isotopic compositions may have been altered from the original to some extent. We previously determined both the concentrations and stable isotopic compositions of nitrate in four sets of the same brand of bottled water (Rishiri water) sold at supermarkets together with those sampled directly at the source well (Meisui factory) (Tsunogai et al., 2010). The differences between the average concentrations, $\delta^{15} \mathrm{~N}, \delta^{18} \mathrm{O}$ and $\Delta{ }^{17} \mathrm{O}$ in the bottled water and those in water from the source well were less than $2 \%, 0.2 \%, 0.2 \%$, and $0.2 \%$, respectively (Tsunogai et al., 2010). Because the Rishiri water had been sterilized by a combination of filtration and heating 
Table 1. Sample descriptions.

\begin{tabular}{|c|c|c|c|c|c|}
\hline No. & Name & Location & Bottled date & Sterilization $^{\mathrm{a}}$ & Note \\
\hline & Japan & & & & \\
\hline 1 & Rishiri water ${ }^{b}$ & Rishiri, Hokkaido, Japan & 18 Mar 2009 & $\mathrm{~F} \& \mathrm{H}$ & \\
\hline 2 & Furano natural water & Furano, Hokkaido, Japan & 10 Oct 2008 & $\mathrm{H}$ & \\
\hline 3 & Moiwa natural water & Sapporo, Hokkaido, Japan & $28 \mathrm{Jul} 2008$ & $\mathrm{~F} \& \mathrm{H}$ & \\
\hline 4 & Niseko water & Iwanai, Hokkaido, Japan & 3 Mar 2009 & $\mathrm{H}$ & \\
\hline 5 & Sapporo water & Sapporo, Hokkaido, Japan & 23 May 2008 & $\mathrm{H}$ & \\
\hline 6 & Yotei Spring & Kyougoku, Hokkaido, Japan & 6 Jan 2009 & $\mathrm{H}$ & \\
\hline 7 & Okushiri water & Okushiri, Hokkaido, Japan & 11 Dec 2008 & $\mathrm{H}$ & \\
\hline 8 & Yumemizuki & Nanae, Hokkaido, Japan & 10 Feb 2008 & $\mathrm{~F}$ & \\
\hline 9 & Ryusendo water & Iwaizumi, Iwate, Japan & $30 \mathrm{Jul} 2008$ & $\mathrm{~F}$ & subterranean lake \\
\hline 10 & Okushimizu & Kiso, Nagano, Japan & 1 Aug 2008 & $\mathrm{H}$ & \\
\hline 11 & Gorogoro water & Tenkawa, Nara, Japan & 5 Aug 2008 & $\mathrm{~F}$ & \\
\hline 12 & Hou-jun-sui & Nobeoka, Miyazaki, Japan & 2 Sep 2008 & $\mathrm{H}$ & \\
\hline 13 & Hotspring 99 & Tarumi, Kagoshima, Japan & 4 Aug 2008 & $\mathrm{H}$ & hot spring $\left(47^{\circ} \mathrm{C}\right)$ \\
\hline 14 & Joumon water & Yakushima, Kagoshima, Japan & 15 Sep 2008 & $\mathrm{~F} \& \mathrm{H}$ & \\
\hline \multirow[t]{2}{*}{15} & Higashi-son water & Higashi-son, Okinawa, Japan & 28 Nov 2007 & $\mathrm{~F} \& \mathrm{H}$ & \\
\hline & Asia & & & & \\
\hline 16 & Tibetan Magic Water & Gangba County, Tibet, China & 26 Sep 2010 & $\mathrm{~F}$ & \\
\hline 17 & $\operatorname{mim}$ & Kedah Darul Aman, Malaysia & 1 Nov 2010 & RO & treated tap water \\
\hline 18 & Water 0 & Kandal, Cambodia & 1 Sep 2010 & UV & \\
\hline 19 & Aura & Chiang Mai, Thailand & 21 Dec 2010 & NS & \\
\hline 20 & Natural Spring & Solan, Himachal Praesh, India & 1 Feb 2011 & - & \\
\hline \multirow[t]{2}{*}{21} & Damla & Uludag, Turkey & 15 Dec 2010 & - & \\
\hline & Africa & & & & \\
\hline 22 & Aqualine & Zaghouan, Tunisia & 28 Oct 2011 & - & \\
\hline 23 & diMA & Tajerouine, Tunisia & 1 Nov 2011 & - & \\
\hline \multirow[t]{2}{*}{24} & safia & El Ksour, Tunisia & 8 Nov 2011 & - & \\
\hline & South America & & & & \\
\hline 25 & Vital & - , Bolivia & 3 Feb 2011 & - & \\
\hline 26 & cielo & Cielo, Peru & 25 Jun 2011 & - & \\
\hline 27 & san luis & Lima, Peru & 18 Jul 2011 & - & \\
\hline 28 & Vivant & Lima, Peru & 26 Jun 2011 & - & \\
\hline \multirow[t]{2}{*}{29} & SOCOSANI & Arequipa, Peru & 8 Apr 2011 & F\&UV & \\
\hline & Europe & & & & \\
\hline 30 & Iceland spring & Heidmörk, Reykjavík, Iceland & 1 Mar 2008 & $\mathrm{~F}$ & \\
\hline 31 & VOSS & Voss, Norway & 10 Feb 2011 & NS & glass bottle \\
\hline 32 & Rosbacher & Bad Vilbel, Germany & 27 May 2011 & NS & \\
\hline 33 & Dobra Voda & Bynov, Czech Republic & 24 Jun 2011 & - & \\
\hline 34 & Bonaqua & Piestany, Slovakia & 25 Oct 2010 & - & \\
\hline 35 & Vittel & Vittel, France & 25 Feb 2011 & NS & \\
\hline 36 & Contrex & Contrexéville, France & 11 Feb 2011 & NS & \\
\hline 37 & Volvic & Auvergne, France & 23 May 2010 & NS & \\
\hline 38 & Perrier & Vergèze, France & 3 May 2011 & NS & glass bottle \\
\hline 39 & PARADISO & Friuli-Venezia Giulia, Italy & 31 Jul 2011 & NS & \\
\hline 40 & ACQUA Filette & Filette, Guarcino, Italy & 1 Mar 2008 & NS & \\
\hline 41 & S. Maria degli Angeli & Rionero in Vulture, Italy & 1 Apr 2011 & - & \\
\hline 42 & Jana & Sveta Jana, Croatia & 18 Jun 2011 & NS & \\
\hline 43 & Studena & Lipik, Croatia & 28 Nov 2010 & NS & \\
\hline 44 & SUZA & Kolasin, Monteneguro & 19 May 2011 & - & \\
\hline 45 & UJË I MIRË & Kllokot, Kosovo & 28 Mar 2011 & - & \\
\hline 46 & Jeta & Kllokot, Kosovo & 17 Dec 2011 & - & \\
\hline 47 & GORSKA & Konopishte, Makedonija & 30 May 2011 & $\mathrm{~F}$ & \\
\hline 48 & Spring Nepravishta & Nepravishta, Albania & 17 Apr 2011 & - & \\
\hline 49 & Loutraki & Loutraki, Greece & 13 May 2011 & NS & \\
\hline
\end{tabular}

a NS: non-sterile water; UV: ultraviolet irradiated; H: heated; F: filtered $(0.45 \mu \mathrm{m}$ or $0.2 \mu \mathrm{m})$; RO: filtered through a reverse osmosis membrane; - : treatments not publically available.

b Data from Tsunogai et al. (2010). 

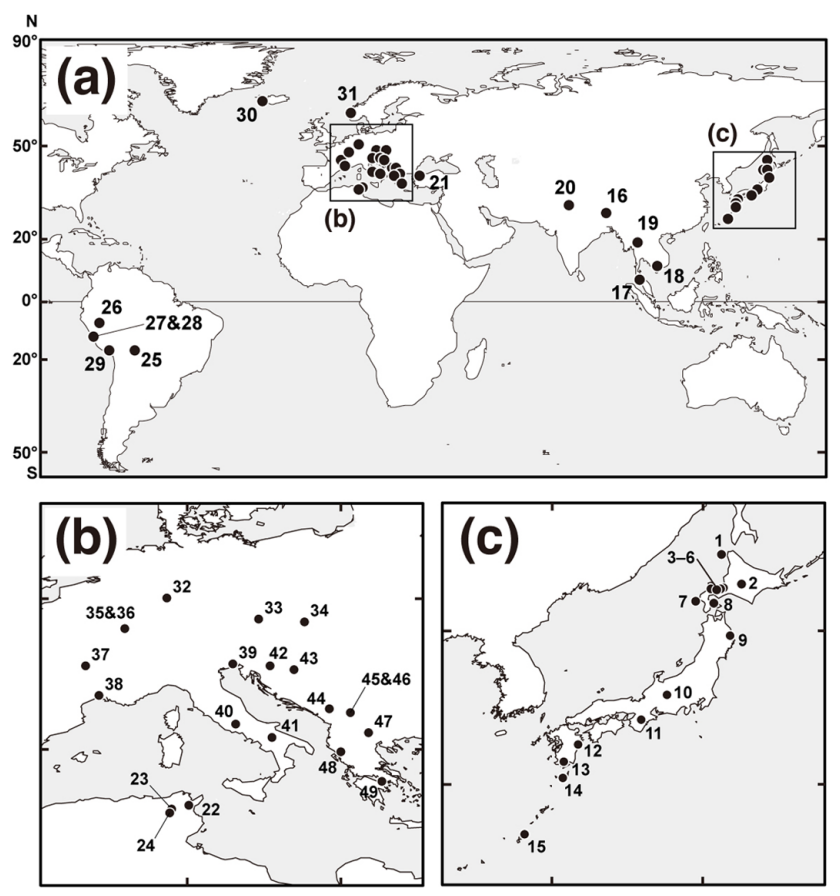

Fig. 1. Maps showing the distribution of the source wells worldwide (a), and regionally (b) and (c).

(Table 1), we concluded that alternations in both concentrations and stable isotopic compositions of nitrate in response to these treatments were small enough to enable bottled water to serve as samples of its source groundwater.

In addition to filtration and heating, some of the samples were sterilized by UV radiation for several seconds (Table 1). UV sterilization could reduce nitrate and increase both the $\delta^{15} \mathrm{~N}$ and $\delta^{18} \mathrm{O}$ of residual nitrate; however, the extent of any reduction during the short reaction period would be small because the decomposition rates of nitrate estimated for the wastewater treatments were small, especially under neutral conditions (Kosaka et al., 2002). Moreover, the triple oxygen isotopic compositions remained stable during the reduction. Therefore, we used these UV sterilized samples to represent groundwater from each site. However, caution should be taken before applying the values obtained from such samples to detailed discussions, especially those based on the values of $\delta^{15} \mathrm{~N}$ and $\delta^{18} \mathrm{O}$.

Many of the bottled water samples produced in North America and Asia were sterilized using ozone, which is known to cause large ${ }^{17} \mathrm{O}$ anomalies (Mauersberger et al., 1999). To exclude those with altered triple oxygen isotopic compositions of nitrate, bottled water sterilized using ozone was excluded. As a result, no samples from North America were evaluated (Fig. 1).

\subsection{Analysis}

The concentration of nitrate together with chloride and other major anions was determined by ion chromatography. The stable isotopic compositions were then determined by converting the nitrate in each sample to $\mathrm{N}_{2} \mathrm{O}$ using the chemical method originally developed to determine the ${ }^{15} \mathrm{~N} /{ }^{14} \mathrm{~N}$ and ${ }^{18} \mathrm{O} /{ }^{16} \mathrm{O}$ isotope ratios of seawater and freshwater nitrate (Mcllvin and Altabet, 2005), with modifications (Tsunogai et al., 2008, 2010, 2011).

The stable isotopic compositions were determined for $\mathrm{N}_{2} \mathrm{O}$ using our Continuous-Flow Isotope Ratio MassSpectrometry (CF-IRMS) system (Tsunogai et al., 2008; Hirota et al., 2010), which consists of an original helium purge and trap line, a gas chromatograph (Agilent 6890) and a Finnigan MAT 252 (Thermo Fisher Scientific, Waltham, MA, USA) with a modified Combustion III interface (Tsunogai et al., 2000, 2002, 2005) and a specially designed multicollector system (Komatsu et al., 2008). An aliquot of $\mathrm{N}_{2} \mathrm{O}$ was introduced, purified, and then carried continuously into the mass spectrometer via an open split interface to monitor isotopologues of $\mathrm{N}_{2} \mathrm{O}^{+}$at $\mathrm{m} / \mathrm{z}$ ratios of 44,45 and 46 to determine $\delta^{45}$ and $\delta^{46}$. Each analysis was calibrated using a machine-working reference gas $\left(99.999 \% \mathrm{~N}_{2} \mathrm{O}\right)$ that was introduced into the mass spectrometer via an open split interface according to a definite schedule to correct for sub-daily temporal variations in the mass spectrometry. In addition, a working-standard gas mixture containing a known concentration of $\mathrm{N}_{2} \mathrm{O}$ (ca. $1000 \mathrm{ppm} \mathrm{N}_{2} \mathrm{O}$ in air) that was injected from a sampling loop was analyzed in the same way as the samples at least once a day to correct for daily temporal variations in the mass spectrometry.

After the analyses based on $\mathrm{N}_{2} \mathrm{O}^{+}$monitoring, another aliquot of $\mathrm{N}_{2} \mathrm{O}$ was introduced to determine the $\Delta^{17} \mathrm{O}$ for $\mathrm{N}_{2} \mathrm{O}$ (Komatsu et al., 2008). Using the same procedures as those used in the $\mathrm{N}_{2} \mathrm{O}^{+}$monitoring mode, purified $\mathrm{N}_{2} \mathrm{O}$ was introduced into our original gold tube unit (Komatsu et al., 2008), which was held at $780^{\circ} \mathrm{C}$ for the thermal decomposition of $\mathrm{N}_{2} \mathrm{O}$ to $\mathrm{N}_{2}$ and $\mathrm{O}_{2}$. The produced $\mathrm{O}_{2}$ purified from $\mathrm{N}_{2}$ was subjected to CF-IRMS to determine the $\delta^{33}$ and $\delta^{34}$ by simultaneous monitoring of $\mathrm{O}_{2}^{+}$isotopologues at $\mathrm{m} / \mathrm{z}$ ratios of 32, 33 and 34. Each analysis was calibrated with a machine-working reference gas $\left(99.999 \% \mathrm{O}_{2}\right.$ gas in a cylinder) that was introduced into the mass spectrometer via an open split interface according to a definite schedule to correct for sub-daily temporal variations in the mass spectrometry. In addition, a working-standard gas mixture containing $\mathrm{N}_{2} \mathrm{O}$ of known concentration (ca. $1000 \mathrm{ppm} \mathrm{N}_{2} \mathrm{O}$ in air) that was injected from a sampling loop was analyzed in the same way as the samples at least once a day to correct for daily temporal variations in the mass spectrometry.

The obtained values of $\delta^{15} \mathrm{~N}, \delta^{18} \mathrm{O}$ and $\Delta^{17} \mathrm{O}$ for $\mathrm{N}_{2} \mathrm{O}$ derived from the nitrate in each sample were compared with those derived from our local laboratory nitrate standards that had been calibrated using the internationally 
distributed isotope reference materials (USGS-34 and USGS-35) (Böhlke et al., 2003; Kaiser et al., 2007) to calibrate the $\delta$ values of the sample nitrate to an international scale, as well as to correct for both the isotope fractionation during the chemical conversion to $\mathrm{N}_{2} \mathrm{O}$ and the progress of oxygen isotope exchange between the nitrate-derived reaction intermediate and water (ca. 20\%). All $\delta$ values are expressed relative to air (for nitrogen) and VSMOW (for oxygen) in this paper.

In this study, we adopted the internal standard method for accurate calibrations to determine the $\delta^{15} \mathrm{~N}, \delta^{18} \mathrm{O}$ or $\Delta^{17} \mathrm{O}$ values of $\mathrm{N}_{2} \mathrm{O}$ derived from our laboratory nitrate standards. Specifically, we added each of the nitrate standard solutions (containing ca. $10 \mathrm{mmol} \mathrm{L}^{-1}$ nitrate with known $\delta^{15} \mathrm{~N}, \delta^{18} \mathrm{O}$ or $\Delta^{17} \mathrm{O}$ values) to additional aliquots of the samples until the nitrate concentration was 3 to 5 times larger than the original, and then converted it to $\mathrm{N}_{2} \mathrm{O}$ and determined the values of $\delta^{15} \mathrm{~N}, \delta^{18} \mathrm{O}$ or $\Delta^{17} \mathrm{O}$ in a similar manner as was used for each pure sample. After correcting the contribution of $\mathrm{N}_{2} \mathrm{O}$ from the nitrate in each sample, we could obtain the stable isotopic compositions for $\mathrm{N}_{2} \mathrm{O}$ derived from our laboratory nitrate standards. The $\delta^{15} \mathrm{~N}, \delta^{18} \mathrm{O}$ and $\Delta^{17} \mathrm{O}$ values in the samples were then simply calibrated using calibration curves generated from the $\mathrm{N}_{2} \mathrm{O}$ derived from the nitrate standards.

Most samples had nitrate concentrations of more than $1 \mu \mathrm{molL} \mathrm{L}^{-1}$, which corresponds to nitrate quantities of more than $30 \mathrm{nmol}$ in a $30 \mathrm{~mL}$ sample and is sufficient to determine $\delta^{15} \mathrm{~N}, \delta^{18} \mathrm{O}$ and $\Delta^{17} \mathrm{O}$ values with high precision. Indeed, we even attained similar high precision for nitrate-depleted samples showing concentrations of less than $1 \mu \mathrm{molL}^{-1}$ through repeated measurements using another aliquot of water. Thus, all isotopic data presented in this study have an error better than $\pm 0.3 \%$ o for $\delta^{15} \mathrm{~N}, \pm 0.5 \%$ o for $\delta^{18} \mathrm{O}$ and $\pm 0.2 \%$ for $\Delta^{17} \mathrm{O}$.

Because we used the more precise power law (Eq. 1) to calculate $\Delta^{17} \mathrm{O}$, the estimated $\Delta^{17} \mathrm{O}$ values were somewhat different from those estimated based on traditional linear approximation (Michalski et al., 2002). While the differences were insignificant for groundwater samples newly evaluated in this study (less than $0.05 \%$ ), the differences would be $0.9 \pm 0.2 \%$ for the $\Delta^{17} \mathrm{O}$ values of $\mathrm{NO}_{3 \mathrm{~atm}}^{-}$(Tsunogai et al., 2010). When using the linearly approximated $\Delta^{17} \mathrm{O}$ values of $\mathrm{NO}_{3 \text { atm }}^{-}$available in the literature, we recalculated the $\Delta^{17} \mathrm{O}$ values based on the power law.

Nitrite $\left(\mathrm{NO}_{2}^{-}\right)$in the samples also interferes with the final $\mathrm{N}_{2} \mathrm{O}$ produced (Mcllvin and Altabet, 2005) when the chemical conversion method is used to determine the stable isotopic compositions of nitrate $\left(\mathrm{NO}_{3}^{-}\right)$. Therefore, it was necessary to correct for the contribution to accurately determine stable isotopic compositions of the sample nitrate. However, all samples analyzed in this study were originally for drinking water, and were characterized by oxic conditions and little biological activity. As a result, they contained $\mathrm{NO}_{2}^{-}$ at concentrations less than the detection limit, which corre-
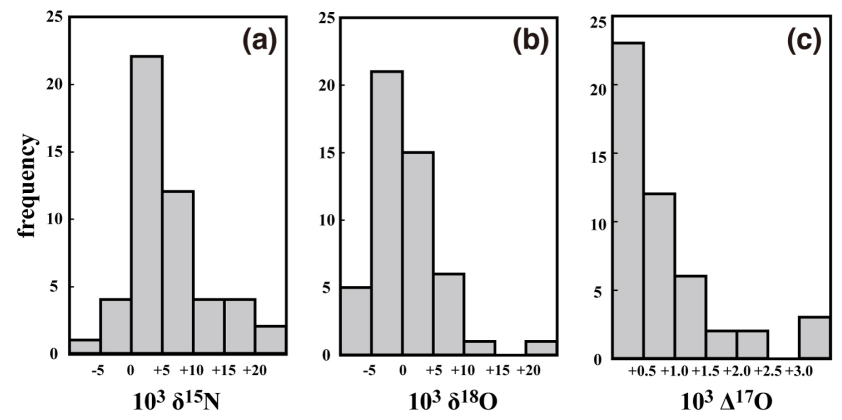

Fig. 2. Histograms of the $\delta^{15} \mathrm{~N}$ (a), $\delta^{18} \mathrm{O}$ (b), and $\Delta^{17} \mathrm{O}$ (c) of nitrate in the bottled mineral water samples. Those classified to the outside of each histogram were included in the nearby uppermost/lowermost classes.

sponded to $\mathrm{NO}_{2}^{-} / \mathrm{NO}_{3}^{-}$ratios less than $10 \%$. Thus the results were used without any corrections.

The $\delta \mathrm{D}$ and $\delta^{18} \mathrm{O}$ values of $\mathrm{H}_{2} \mathrm{O}$ in the samples were also analyzed using Cavity Ring-Down Spectroscopy (Picarro L2120-I with an A0211 vaporizer and autosampler) within an error of $\pm 0.1 \%$. Both VSMOW and VSLAP were used to calibrate the values to the international scale.

\section{Results and discussion}

\subsection{Groundwater nitrate: overview}

The concentrations and $\delta^{15} \mathrm{~N}, \delta^{18} \mathrm{O}$, and $\Delta^{17} \mathrm{O}$ values of nitrate in the samples are presented in Table 2 with their $\mathrm{Cl}$ concentrations and the $\delta^{2} \mathrm{O}$ and $\delta^{18} \mathrm{O}$ values of water. We could not determine the $\Delta^{17} \mathrm{O}$ values of nitrate for one of the water samples (No. 18) that had a nitrate concentration of less than $0.3 \mu \mathrm{molL}^{-1}$.

The average and $1 \sigma$ variation for concentration, $\delta^{15} \mathrm{~N}$, and $\delta^{18} \mathrm{O}$ of nitrate were $84 \pm 197 \mu \mathrm{molL}^{-1},+5.8 \pm 6.6 \%$, and $+1.2 \pm 7.6 \%$, respectively (Table 2, Fig. 2), which are typical values for nitrate in natural groundwater free from artificial pollution (e.g., de Walle and Sevenster, 1998; Hiscock et al., 1991; Kendall, 1998; Moore et al., 2006). A very low $\delta^{15} \mathrm{~N}$ value of $-11 \%$ was found for No. 13. This is a hot spring water with a temperature of $47^{\circ} \mathrm{C}$ at the source well. Some unusual nitrate production such as microbial nitrification could be responsible for the ${ }^{15} \mathrm{~N}$ depletion observed at this site.

The average and maximum $\Delta^{17} \mathrm{O}$ values of nitrate were $+0.8 \%$ and $+4.5 \%$ o, respectively (Table 2, Fig. 2). While most of the samples showed positive $\Delta^{17} \mathrm{O}$ values, seven (Nos. 15, 28, 29, 34, 37, 40, and 45) showed negative $\Delta^{17} \mathrm{O}$ values as low as $-0.2 \%$. Because the $\Delta^{17} \mathrm{O}$ value of tropospheric $\mathrm{O}_{2}$ is around $-0.2 \%$ (Luz and Barkan, 2000), the contribution of the oxygen atom derived from tropospheric $\mathrm{O}_{2}$ during the production of remineralized nitrate from ammonium or organic nitrogen could be partly responsible for 
Table 2. Concentration and stable isotopic compositions $\left(\delta^{15} \mathrm{~N}, \delta^{18} \mathrm{O}\right.$, and $\left.\Delta^{17} \mathrm{O}\right)$ of nitrate dissolved in the bottled water samples, together with the other parameters.

\begin{tabular}{|c|c|c|c|c|c|c|c|c|c|}
\hline No. & $\begin{array}{r}\mathrm{NO}_{3}^{-} \\
\mu \mathrm{mol} \mathrm{L}\end{array}$ & $\begin{array}{r}\delta^{15} \mathrm{~N} \\
\% 0\end{array}$ & $\begin{array}{r}\delta^{18} \mathrm{O} \\
\% \circ\end{array}$ & $\begin{array}{r}\Delta^{17} \mathrm{O} \\
\% 0\end{array}$ & $\begin{array}{r}\mathrm{C}_{\mathrm{atm}} / \mathrm{C}_{\text {total }} \\
\%\end{array}$ & $\begin{array}{r}\mathrm{C}_{\text {atm }} \\
\mu \mathrm{mol} \mathrm{L}\end{array}$ & $\begin{array}{r}\delta^{18} \mathrm{O}_{H 2 O} \\
\% \circ\end{array}$ & $\begin{array}{r}\delta \mathrm{D}_{H 2 O} \\
\% o\end{array}$ & $\mu \mathrm{mol} \mathrm{L}^{-1}$ \\
\hline 1 & 30 & -2.3 & +3.1 & +2.2 & $8.8 \pm 1.7$ & $2.6 \pm 0.6$ & -10.5 & -68.7 & 620 \\
\hline 2 & 11 & +1.6 & -6.4 & +0.6 & $2.3 \pm 1.0$ & $0.3 \pm 0.1$ & -9.8 & -76.7 & 163 \\
\hline 3 & 32 & +5.6 & -3.4 & +0.7 & $2.6 \pm 1.0$ & $0.8 \pm 0.3$ & -9.4 & -67.8 & 196 \\
\hline 4 & 11 & +1.7 & +0.4 & +1.4 & $5.7 \pm 1.3$ & $0.6 \pm 0.2$ & -8.8 & -62.3 & 287 \\
\hline 5 & 27 & +5.3 & -1.1 & +0.6 & $2.3 \pm 1.0$ & $0.6 \pm 0.3$ & -10.1 & -70.6 & 293 \\
\hline 6 & 46 & +1.8 & -2.6 & +1.1 & $4.4 \pm 1.2$ & $2.0 \pm 0.6$ & -8.4 & -65.0 & 156 \\
\hline 7 & 27 & +0.1 & -2.1 & +0.3 & $1.3 \pm 0.9$ & $0.3 \pm 0.2$ & -7.3 & -53.0 & 21 \\
\hline 8 & 6.2 & +2.6 & -2.7 & +1.5 & $6.1 \pm 1.4$ & $0.4 \pm 0.1$ & -7.9 & -59.1 & 352 \\
\hline 9 & 49 & +3.7 & -5.3 & +1.0 & $4.1 \pm 1.2$ & $2.0 \pm 0.6$ & -8.5 & -64.2 & 526 \\
\hline 10 & 9.3 & +0.4 & +0.3 & +2.0 & $7.9 \pm 1.6$ & $0.7 \pm 0.2$ & -12.1 & -81.7 & 157 \\
\hline 11 & 58 & -1.4 & +2.0 & +0.8 & $3.2 \pm 1.1$ & $1.9 \pm 0.7$ & -8.0 & -56.4 & 51 \\
\hline 12 & 26 & +5.0 & -2.0 & +0.3 & $1.1 \pm 0.8$ & $0.3 \pm 0.2$ & -6.1 & -47.2 & 218 \\
\hline 13 & 1.1 & -11.0 & -1.4 & +1.0 & $4.1 \pm 1.2$ & $<0.1$ & -5.9 & -40.5 & 134 \\
\hline 14 & 14 & +2.6 & -0.7 & +1.4 & $5.8 \pm 1.3$ & $0.8 \pm 0.2$ & -4.8 & -33.5 & 228 \\
\hline 15 & 4.8 & +0.7 & +2.5 & -0.2 & $<0.1$ & $<0.1$ & -3.5 & -23.3 & 620 \\
\hline 16 & 9.0 & +1.0 & +6.2 & +4.5 & $17.9 \pm 2.6$ & $1.6 \pm 0.3$ & -18.8 & -140.8 & 9.2 \\
\hline 17 & 1.6 & +9.6 & -4.7 & +0.7 & $3.4 \pm 1.3$ & $<0.1$ & -6.6 & -43.4 & 13 \\
\hline 18 & 0.3 & +19.2 & +44.4 & - & - & - & -7.9 & -56.6 & 527 \\
\hline 19 & 77 & +7.0 & +1.8 & +0.5 & $2.6 \pm 1.2$ & $2.0 \pm 1.0$ & -7.3 & -50.6 & 21 \\
\hline 20 & 21 & +11.9 & -0.2 & +0.0 & $0.0 \pm 0.7$ & $<0.1$ & -6.2 & -41.0 & 58 \\
\hline 21 & 2.0 & -1.2 & -1.5 & +1.4 & $5.6 \pm 1.3$ & $<0.1$ & -10.6 & -68.0 & 21 \\
\hline 22 & 101 & +5.7 & +3.2 & +0.5 & $2.1 \pm 0.9$ & $2.1 \pm 1.0$ & -6.3 & -36.9 & 1819 \\
\hline 23 & 369 & +7.6 & +3.9 & +0.0 & $0.1 \pm 0.7$ & $0.5 \pm 2.6$ & -7.4 & -49.9 & 849 \\
\hline 24 & 231 & +7.6 & +7.6 & +0.1 & $0.3 \pm 0.7$ & $0.6 \pm 1.7$ & -7.5 & -48.6 & 543 \\
\hline 25 & 33 & +15.4 & -3.4 & +0.1 & $0.5 \pm 0.9$ & $0.2 \pm 0.3$ & -15.1 & -115.9 & 83 \\
\hline 26 & 87 & +10.7 & -2.1 & +0.4 & $2.0 \pm 1.1$ & $1.7 \pm 1.0$ & -14.1 & -106.9 & 471 \\
\hline 27 & 28 & +8.9 & +0.7 & +0.4 & $1.9 \pm 1.1$ & $0.5 \pm 0.3$ & -13.6 & -102.5 & 158 \\
\hline 28 & 1271 & +8.7 & -5.7 & -0.0 & $<1.1$ & $<15.1$ & -13.9 & -104.5 & 2143 \\
\hline 29 & 6.3 & +11.6 & -6.6 & -0.0 & $<1.1$ & $<0.1$ & -13.7 & -100.9 & 6025 \\
\hline 30 & 3.4 & +0.2 & +1.0 & +2.2 & $7.4 \pm 1.3$ & $0.3 \pm 0.1$ & -5.9 & -50.6 & 282 \\
\hline 31 & 3.0 & +3.6 & +9.0 & +3.9 & $13.2 \pm 1.8$ & $0.4 \pm 0.1$ & -9.1 & -63.7 & 324 \\
\hline 32 & 4.7 & +5.8 & -5.1 & +0.0 & $0.1 \pm 0.6$ & $<0.1$ & -8.8 & -61.9 & 1564 \\
\hline 33 & 73 & +5.9 & -1.9 & +0.3 & $1.1 \pm 0.8$ & $0.8 \pm 0.6$ & -11.0 & -79.1 & 16 \\
\hline 34 & 84 & +4.9 & -0.2 & -0.1 & $<0.5$ & $<0.4$ & -10.4 & -72.9 & 39 \\
\hline 35 & 0.3 & +15.5 & -4.0 & +0.3 & $1.0 \pm 0.8$ & $<0.1$ & -8.3 & -57.3 & 98 \\
\hline 36 & 41 & +13.3 & +1.5 & +0.3 & $1.2 \pm 0.8$ & $0.5 \pm 0.4$ & -8.0 & -53.9 & 289 \\
\hline 37 & 123 & +4.0 & -1.6 & -0.2 & $<0.1$ & $<0.2$ & -9.0 & -58.8 & 394 \\
\hline 38 & 133 & +6.7 & +3.6 & +0.3 & $1.4 \pm 0.9$ & $1.8 \pm 1.2$ & -6.3 & -39.4 & 647 \\
\hline 39 & 332 & +3.6 & +2.7 & +0.6 & $2.5 \pm 1.0$ & $8.5 \pm 3.5$ & -8.0 & -53.8 & 158 \\
\hline 40 & 3.8 & +23.0 & -3.8 & -0.0 & $<0.8$ & $<0.1$ & -6.2 & -42.7 & 128 \\
\hline 41 & 433 & +1.9 & -0.8 & +0.2 & $0.9 \pm 0.8$ & $4.0 \pm 3.5$ & -8.1 & -53.7 & 185 \\
\hline 42 & 16 & +4.4 & +9.2 & +0.1 & $0.2 \pm 0.7$ & $<0.2$ & -10.9 & -73.6 & 24 \\
\hline 43 & 16 & +1.6 & +6.3 & +3.6 & $14.5 \pm 2.3$ & $2.3 \pm 0.5$ & -9.6 & -65.9 & 46 \\
\hline 44 & 8.2 & -1.2 & -1.1 & +0.9 & $3.7 \pm 1.1$ & $0.3 \pm 0.1$ & -9.8 & -62.0 & 15 \\
\hline 45 & 20 & +22.4 & +6.5 & -0.0 & $<0.8$ & $<0.2$ & -10.6 & -72.6 & 203 \\
\hline 46 & 12 & +18.4 & +11.6 & +0.1 & $0.4 \pm 0.8$ & $<0.2$ & -10.5 & -72.2 & 198 \\
\hline 47 & 9.2 & +1.4 & +1.7 & +0.8 & $3.1 \pm 1.0$ & $0.3 \pm 0.1$ & -9.8 & -61.5 & 19 \\
\hline 48 & 96 & +4.8 & +0.8 & +0.5 & $2.1 \pm 0.9$ & $2.0 \pm 1.0$ & -7.1 & -43.0 & 47 \\
\hline 49 & 106 & +4.4 & -2.4 & +0.7 & $2.7 \pm 1.0$ & $2.8 \pm 1.1$ & -6.3 & -39.4 & 470 \\
\hline Avg. & $\begin{array}{r}84 \\
\pm 197\end{array}$ & $\begin{array}{l}+5.8 \\
\pm 6.6\end{array}$ & $\begin{array}{l}+1.2 \\
\pm 7.6\end{array}$ & $\begin{array}{l}+0.8 \\
\pm 1.0\end{array}$ & $3.1 \pm 3.9$ & - & - & - & $447 \pm 927$ \\
\hline
\end{tabular}

- : not determined 


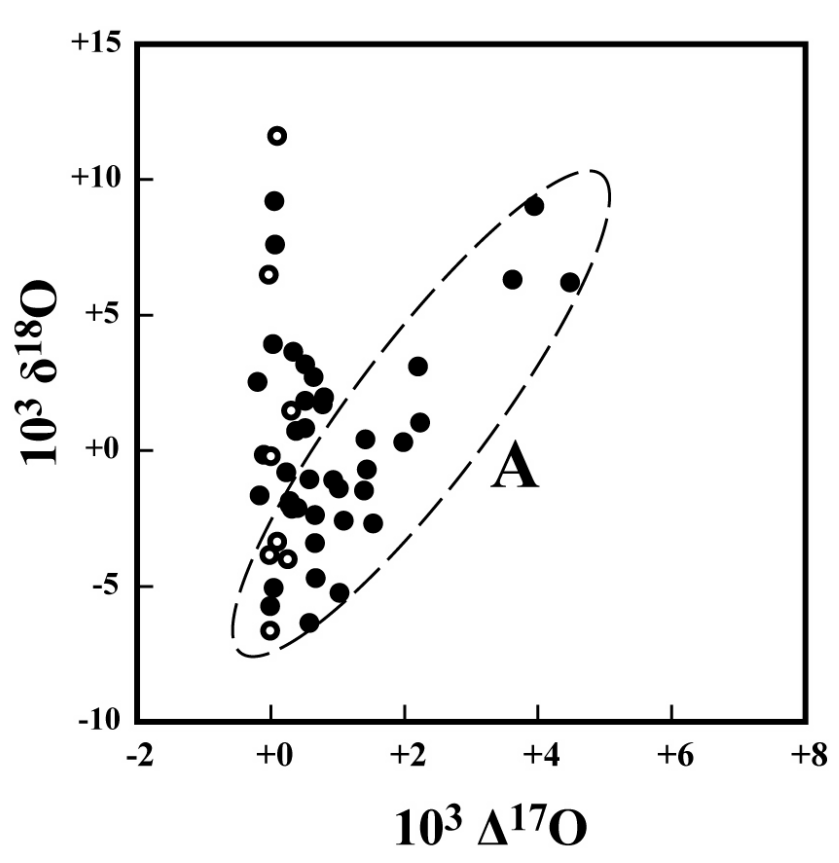

Fig. 3. Relationship between $\Delta^{17} \mathrm{O}$ and $\delta^{18} \mathrm{O}$ in $\mathrm{NO}_{3}^{-}$from bottled water samples. The open circles denote those showing $\delta^{15} \mathrm{~N}$ values of more than $+11 \%$.

the observed negative $\Delta^{17} \mathrm{O}$ values less than 0 . However, even if the contribution was significant, the possible $\Delta^{17} \mathrm{O}$ value of produced remineralized nitrate would include $0 \%$ o within the error of our analytical precision $( \pm 0.2 \%$ ) . Accordingly, $0 \%$ is used for the $\Delta^{17} \mathrm{O}$ value of remineralized nitrate and observed $\Delta^{17} \mathrm{O}$ values less than $0 \%$ are considered to be $0 \%$ for the remainder of this paper. In other words, possible errors in our further discussions derived from the deviations in the $\Delta^{17} \mathrm{O}$ values of remineralized nitrate from $0 \%$ o were included within the error of the analyses.

To verify that atmospheric nitrate was responsible for the elevated $\Delta^{17} \mathrm{O}$ values up to $4.5 \%$ in the samples, the $\delta^{18} \mathrm{O}$ values of nitrate in the samples were plotted as a function of $\Delta^{17} \mathrm{O}$ (Fig. 3). Because atmospheric nitrate is also enriched in ${ }^{18} \mathrm{O}$ (Durka et al., 1994; Kendall, 1998), we can anticipate ${ }^{18} \mathrm{O}$ enrichment for those showing elevated $\Delta^{17} \mathrm{O}$ values. As shown in Fig. 3, those showing high $\Delta^{17} \mathrm{O}$ values always accompanied high $\delta^{18} \mathrm{O}$ values; thus, we can find a linear correlation for the samples categorized as Group A in the figure. By extrapolating the linear correlation to the region of $\mathrm{NO}_{3 \mathrm{~atm}}^{-}$having $\Delta^{17} \mathrm{O}=+20$ to $+30 \%$, we obtain $\delta^{18} \mathrm{O}=+80 \pm 30 \%$, which corresponds to the values for $\mathrm{NO}_{3 \mathrm{~atm}}^{-}$(Durka et al., 1994; Morin et al., 2009; Alexander et al., 2009; Tsunogai et al., 2010). These findings indicate that the $\delta^{18} \mathrm{O}$ values primarily reflect the contribution of $\mathrm{NO}_{3 \text { atm }}^{-}$as well as $\Delta^{17} \mathrm{O}$ for the samples in Group A.

Conversely, data plotted outside of Group A (hereafter referred to as Group B) did not present such a linear correlation. While they showed ${ }^{18} \mathrm{O}$ enrichment up to $+11.6 \%$ o in $\delta^{18} \mathrm{O}$, the $\Delta^{17} \mathrm{O}$ values were always close to $0 \%$. Although the $\Delta{ }^{17} \mathrm{O}$ values of nitrate are stable during the postdepositional isotopic fractionation processes, the $\delta^{18} \mathrm{O}$ values of nitrate can vary. The isotopic fractionations during the partial removal through nitrate uptake or denitrification likely play a significant role in the ${ }^{18} \mathrm{O}$ enrichment because many of the ${ }^{18} \mathrm{O}$-enriched samples in Group B showed the ${ }^{15} \mathrm{~N}$-enriched $\delta^{15} \mathrm{~N}$ values of more than $+11 \%$ (Fig. 3).

As shown in Fig. 3, some data in Group B did not show ${ }^{15} \mathrm{~N}$ enrichment, despite showing ${ }^{18} \mathrm{O}$ enrichment of up to $+9.2 \%$. Without the $\Delta^{17} \mathrm{O}$ data for these samples, such ${ }^{18} \mathrm{O}-$ enrichment would be interpreted as the result of the contribution of atmospheric nitrate (Durka et al., 1994). However, since the $\Delta^{17} \mathrm{O}$ values of these samples were close to zero, we must assume alternative processes for them, such as reducing $\delta^{15} \mathrm{~N}$ values through the contribution of some highly ${ }^{15} \mathrm{~N}$-depleted nitrate as well as their partial removal through nitrate uptake or denitrification. The presence of such data implies that interpretation based only on the values of $\delta^{18} \mathrm{O}$ and $\delta^{15} \mathrm{~N}$ of nitrate is not always straightforward. Accordingly, $\Delta{ }^{17} \mathrm{O}$ data would be essential to quantify the contribution of atmospheric nitrate in the hydrosphere.

\subsection{Mixing ratios of atmospheric nitrate within total nitrate in groundwater}

The $\Delta^{17} \mathrm{O}$ data of nitrate in each sample can be used to estimate the mixing ratio of $\mathrm{NO}_{3}^{-}$atm to total $\mathrm{NO}_{3}^{-}\left(\mathrm{C}_{\text {total }}\right)$ in each groundwater sample by applying Eq. (2):

$\frac{\mathrm{C}_{\mathrm{atm}}}{\mathrm{C}_{\text {total }}}=\frac{\Delta^{17} \mathrm{O}}{\Delta^{17} \mathrm{O}_{\mathrm{avg}}}$,

where $\mathrm{C}_{\mathrm{atm}} / \mathrm{C}_{\text {total }}$ is the mixing ratio of $\mathrm{NO}_{3 \text { atm }}^{-}$to $\mathrm{NO}_{3 \text { total }}^{-}$ and $\Delta^{17} \mathrm{O}_{\text {avg }}$ denotes the average $\Delta^{17} \mathrm{O}$ value of $\mathrm{NO}_{3 \mathrm{~atm}}^{-}$ (Tsunogai et al., 2010). In a previous $\Delta^{17} \mathrm{O}$ study conducted on Rishiri Island, we used the $\Delta^{17} \mathrm{O}_{\text {avg }}$ value obtained through continuous monitoring on the island. However, in this study, the $\Delta^{17} \mathrm{O}_{\text {avg }}$ value at each recharge area was not available for most samples. Because the $\Delta^{17} \mathrm{O}$ value of atmospheric nitrate varies primarily as a result of the reaction path from NO to nitrate in the atmosphere (Michalski et al., 2003; Morin et al., 2009; Alexander et al., 2009), it is difficult to apply the values obtained from monitoring at distant sta-

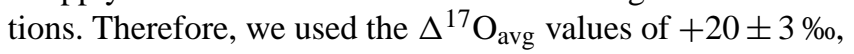
$+25 \pm 3 \%$, and $+30 \pm 3 \%$ or for samples collected at latitudes of $20^{\circ} \mathrm{S}$ to $20^{\circ} \mathrm{N}, 20^{\circ} \mathrm{N}$ to $50^{\circ} \mathrm{N}$, and $50^{\circ} \mathrm{N}$ to $70^{\circ} \mathrm{N}$, respectively, based on the global $\Delta^{17} \mathrm{O}$ distribution of atmospheric nitrate estimated by Alexander et al. (2009) as well as those determined in previous investigations of atmospheric nitrate (Michalski et al., 2003; Savarino et al., 2007; Kaiser et al., 2007; Ewing et al., 2007; Kunasek et al., 2008).

Because the $\Delta^{17} \mathrm{O}$ value of $\mathrm{NO}_{3 \mathrm{~atm}}^{-}$is a function of the reaction path from NO to nitrate in the atmosphere (Michalski et al., 2003; Morin et al., 2009; Alexander et al., 2009), 
the $\Delta^{17} \mathrm{O}$ values could be different on days when $\mathrm{NO}_{3}^{-}$atm was deposited in groundwater, especially for that deposited during preindustrial times, when the emission flux of anthropogenic $\mathrm{NO}_{\mathrm{x}}$ was substantially smaller than current levels (Duce et al., 2008). This hypothesis was also supported by the global model of $\Delta^{17} \mathrm{O}$ values of $\mathrm{NO}_{3 \mathrm{~atm}}^{-}$, which shows smaller $\Delta^{17} \mathrm{O}$ values in remote regions than in those close to the source regions at the same latitude (Alexander et al., 2009). However, the regional differences in the annual average $\Delta^{17} \mathrm{O}$ values within the same latitude were less than a few \%o (Alexander et al., 2009), while the highest deposition rate of $\mathrm{NO}_{3 \mathrm{~atm}}^{-}$was more than 10 times that of the lowest. As a result, the historical changes in the $\Delta^{17} \mathrm{O}$ values were included within the error of the $\Delta^{17} \mathrm{O}_{\text {avg }}$ values used in this study. It should be noted that the $\Delta^{17} \mathrm{O}_{\text {avg values }}$ could be revised in the future when a reliable model of the historical changes in the $\Delta^{17} \mathrm{O}$ values is developed. By using the $\Delta{ }^{17} \mathrm{O}_{\text {avg }}$ values, we estimated that, on average, only $3.1 \%$ of the total nitrate in the groundwater samples originates directly from the atmosphere; therefore, the remainder of nitrate is of remineralized origin $\left(\mathrm{NO}_{3 \mathrm{re}}^{-}\right)$and has been produced through biological processing in soils. The average mixing ratio of $\mathrm{NO}_{3 \mathrm{~atm}}^{-}$within the groundwater nitrate was smaller than that estimated in an oligotrophic lake water column in Japan $(9.7 \pm 0.8 \%)$ (Tsunogai et al., 2011). A smaller $\mathrm{C}_{\mathrm{atm}} / \mathrm{C}_{\text {total }}$ ratio corresponds to a larger nitrification rate under the same deposition velocity of atmospheric nitrate (Tsunogai et al., 2011). Accordingly, the results of this study imply rapid turnover, and thus more rapid biological processing of nitrate in forested soils than in the lake water column.

When compared with the average $\mathrm{C}_{\mathrm{atm}} / \mathrm{C}_{\text {total }}$ ratio $(7.4 \pm 2.6 \%)$ estimated for nitrate discharged from natural forested watersheds on Rishiri Island, the average $\mathrm{C}_{\mathrm{atm}} / \mathrm{C}_{\text {total }}$ ratio obtained in this study was much smaller. The value can also be classified to the lower end of those in basic stream flows (3.1 to $7.7 \%$ ) and soil extracts (1.9 to $11.4 \%$ ) in southern California estimated in a past study (Michalski et et al., 2004). The possible reasons for these discrepancies are discusses in Sect. 3.4.

\subsection{Concentrations of atmospheric nitrate in groundwater: implications for recharge zones}

To investigate the processes regulating the mixing ratios of $\mathrm{NO}_{3 \mathrm{~atm}}^{-}$, the absolute concentration of $\mathrm{NO}_{3 \mathrm{~atm}}^{-}\left(\mathrm{C}_{\mathrm{atm}}\right)$ was calculated for each sample using each nitrate concentration $\left(\mathrm{C}_{\text {total }}\right)$ and each $\Delta^{17} \mathrm{O}$ value and employing Eq. (2). The calculated $\mathrm{C}_{\mathrm{atm}}$ is plotted as a function of $\mathrm{C}_{\text {total }}$ for the samples in Fig. 4.

While $\mathrm{C}_{\text {total }}$ varied widely among the samples from 0.3 to $1271 \mu \mathrm{molL}^{-1}, \mathrm{C}_{\mathrm{atm}}$ was relatively uniform around $1.0 \mu \mathrm{molL}^{-1}$ on average, ranging from 0 to $8.5 \pm 3.5 \mu \mathrm{molL}^{-1}$ (sample No. 39). The observed variation in the $\mathrm{C}_{\text {total }}$ was likely primarily due to different contri-

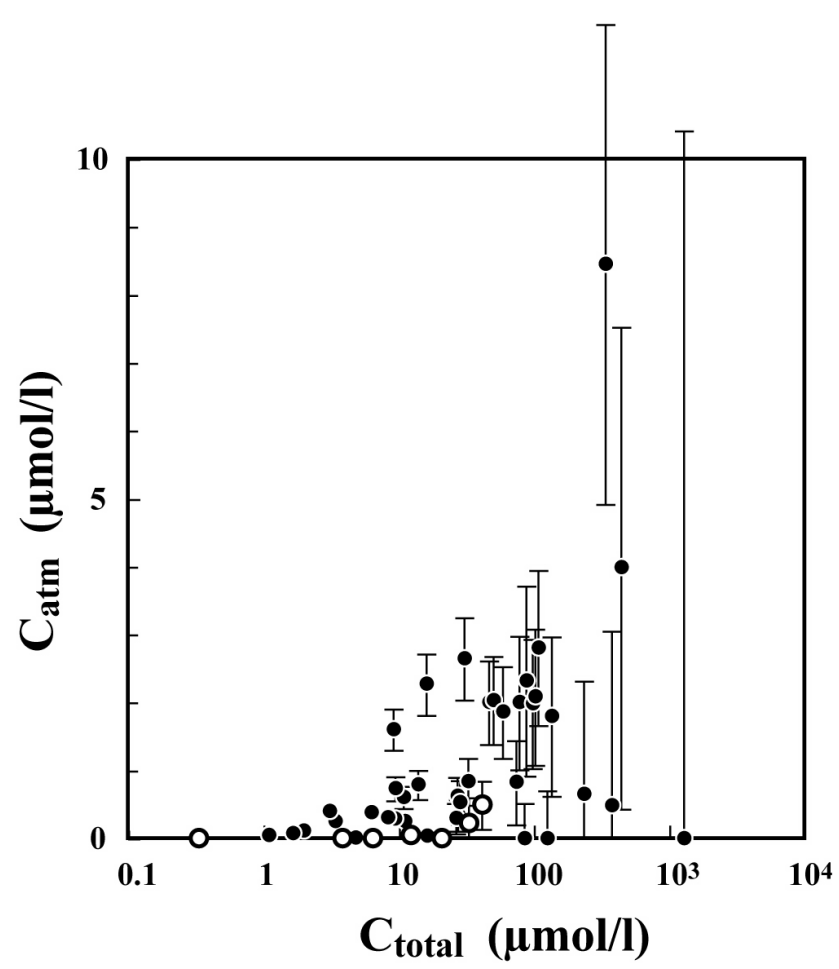

Fig. 4. Calculated concentration of $\mathrm{NO}_{3 \mathrm{~atm}}^{-}\left(\mathrm{C}_{\mathrm{atm}}\right)$ in each water sample plotted as a function of the total $\mathrm{NO}_{3}^{-}$concentration $\left(\mathrm{C}_{\text {total }}\right)$. Open circles denote those showing $\delta^{15} \mathrm{~N}$ values of more than $+11 \%$. Error bars smaller than the symbols were deleted.

butions of $\mathrm{NO}_{3 \mathrm{re}}^{-}$. Specifically, additional contributions of $\mathrm{NO}_{3 \text { re }}^{-}$during groundwater flow through the ground were responsible for the observed differences in $\mathrm{C}_{\text {total }}$ among groundwater samples.

If nitrate was chemically stable during the processes such as deposition into surface ecosystems and flow through the ground, the $\mathrm{C}_{\mathrm{atm}}$ in groundwater would be the same or somewhat higher than that in precipitation (wet deposition) due to both evaporative concentration and the addition of $\mathrm{NO}_{3 \mathrm{~atm}}^{-}$ through dry deposition. However, the estimated $\mathrm{C}_{\text {atm }}$ values were substantially lower than those in precipitation (wet deposition) in general (e.g., Stensland et al., 1986; EANET, 2008). Thus a substantial portion of $\mathrm{NO}_{3}^{-}$atm was reduced during the processes of recharge at the source and subsequent flow through the ground. Here, these reduction processes are discussed based on differences in the $\mathrm{C}_{\mathrm{atm}}$ between samples.

One of the striking features of variations in $\mathrm{C}_{\mathrm{atm}}$ is that samples with $\delta^{15} \mathrm{~N}$ values greater than $+11 \%$ always showed low $\mathrm{NO}_{3 \mathrm{~atm}}^{-}$values (Fig. 4). Because partial removal of nitrate increased the $\delta^{15} \mathrm{~N}$ values of residual nitrate through kinetic fractionation, uptake by plants or microbes and denitrification are likely both responsible for the $\mathrm{NO}_{3}^{-}$atm depletion. In other words, even if $\mathrm{NO}_{3 \mathrm{~atm}}^{-}$was incorporated into groundwater at its recharge zone to some extent, subsequent nitrate reduction through uptake by plants or microbes 

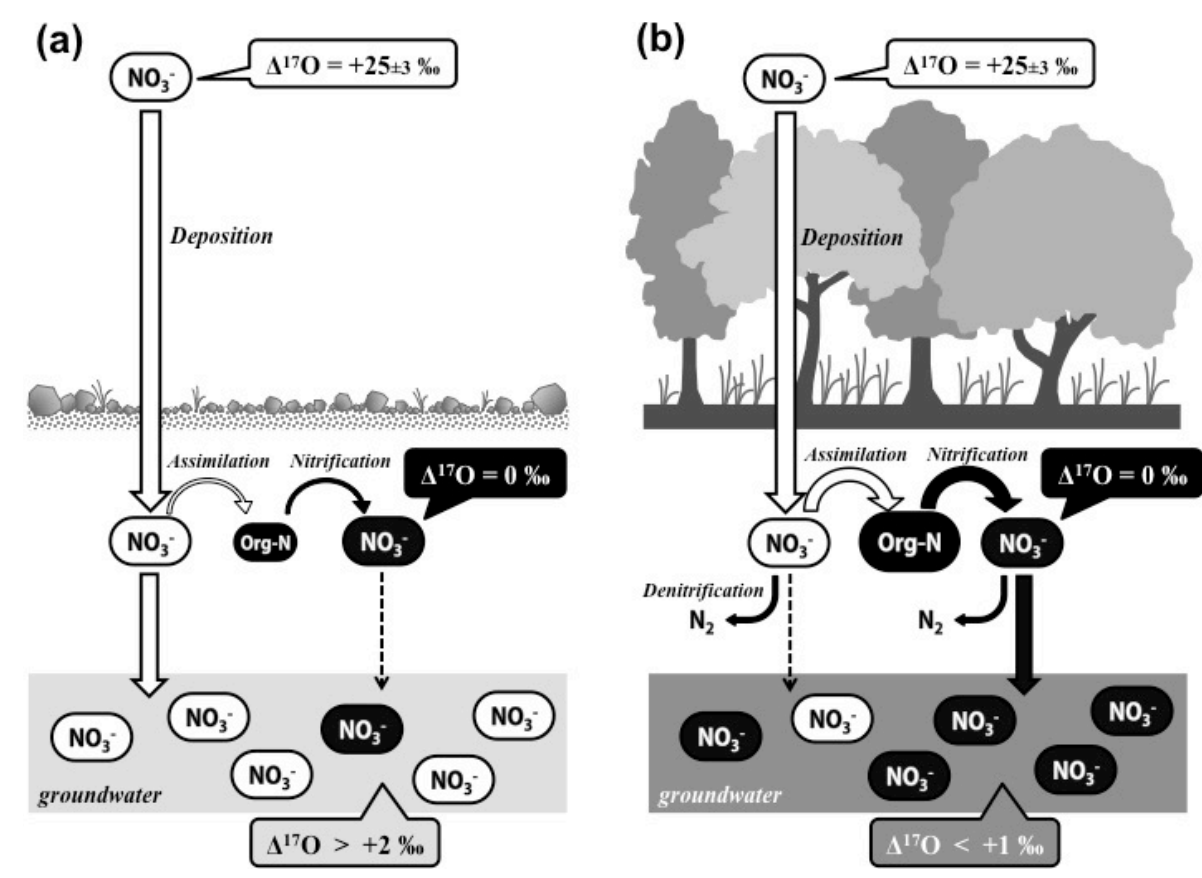

Fig. 5. Schematic diagrams showing the biological processing of atmospheric nitrate in soils covered with little vegetation (a) and high levels of vegetation (b).

and denitrification reduced $\mathrm{NO}_{3 \text { atm }}^{-}$in the groundwater samples.

In addition to post depositional reduction of $\mathrm{NO}_{3 \mathrm{~atm}}^{-}$ within groundwater, vegetation in each recharge area appears to be an important factor influencing $\mathrm{C}_{\text {atm }}$ in groundwater, especially for samples showing elevated $\mathrm{C}_{\mathrm{atm}}$. The most $\mathrm{NO}_{3 \mathrm{~atm}}^{-}$-enriched sample was No. $39\left(8.5 \pm 3.5 \mu \mathrm{molL}^{-1}\right)$. The source spring of No. 39 was Paradiso di Pocenia in northern Italy, at the foot of the Carnic Alps. Thus the mountains in and around the Carnic Alps, which have an elevation of more than $2000 \mathrm{~m}$, are likely the major recharge zone of this groundwater. Accordingly, the rocky surface and low amount of vegetation at the recharge zones are likely responsible for the $\mathrm{NO}_{3 \mathrm{~atm}}^{-}$enrichment owing to the absence of nitrate consumption by soil organisms and trees (Fig. 5). Because $\mathrm{NO}_{3 \text { atm }}^{-}$enrichment was also found at the drainage from damaged forested watersheds in past studies (Durka et al., 1994), $\mathrm{NO}_{3 \mathrm{~atm}}^{-}$enrichment in the samples implies that vegetation and the related surface ecosystem must be highly responsible for the consumption of $\mathrm{NO}_{3 \mathrm{~atm}}^{-}$(Fig. 5).

In addition to No. 39, Nos. $1\left(2.6 \pm 0.6 \mu \mathrm{molL}^{-1}\right)$, $6 \quad\left(2.0 \pm 0.6 \mu \mathrm{molL}^{-1}\right), \quad 9 \quad\left(2.0 \pm 0.6 \mu \mathrm{mol} \mathrm{L}^{-1}\right)$, and $11\left(1.9 \pm 0.7 \mu \mathrm{molL}^{-1}\right)$ from Japan, No. 16 $\left(1.6 \pm 0.3 \mu \mathrm{molL}^{-1}\right)$ from Tibet, China, No. $19(2.0 \pm$ $\left.1.0 \mu \mathrm{molL} \mathrm{m}^{-1}\right)$ from Thailand, No. $22\left(2.1 \pm 1.0 \mu \mathrm{molL}^{-1}\right)$ from Tunisia, No. $43\left(2.3 \pm 0.5 \mu \mathrm{molL}^{-1}\right)$ from Croatia, and No. $49\left(2.8 \pm 1.1 \mu \mathrm{molL}^{-1}\right)$ from Greece showed $\mathrm{C}_{\mathrm{atm}}$ values of $\geq 1.0 \mu \mathrm{molL}^{-1}$. The $\mathrm{NO}_{3 \mathrm{~atm}}^{-}$enrichment in Nos. 1 , $6,16,19,22,43$, and 49 likely occurred for reasons similar to that in No. 39, because the sources of these samples are located in high mountains with little vegetation, such as Mt. Rishiri (1721 m) for No. 1, Mt. Yotei (1898 m) for No. 6, the Himalaya Mountains for No. 16, Doi Suthep $(1676 \mathrm{~m})$ for No. 19, the Dorsale Mountains (1071 m) for No. 22, Psunj (984 m) for No. 43, and the Gerania Mountains (1369 m at Makryplagi) for No. 49. The absence of rainfall in the source area might also be responsible for the low vegetation and thus less nitrate consumption for water samples produced in arid areas, such as Nos. 16 (Tibet, China) and 22 (Tunisia).

The $\mathrm{NO}_{3 \mathrm{~atm}}^{-}$enrichments in Nos. 9 (Ryusendo water) and 11 (Gorogoro water) were somewhat difficult to explain. Ryusendo is a famous stalactite grotto in Japan located on Mt. Ureira (604 m height), which is covered with dense vegetation, and No. 9 is taken directly from one of the deep subterranean lakes in the stalactite grotto; No. 11 is taken directly from a spring in a stalactite grotto (Goyomatsu stalactite grotto) in Nara Prefecture, Japan. While the source stalactite grotto is located at the middle part of Mt. Inamuragatake (1726 m height) at an altitude of $890 \mathrm{~m}$, the majority of the mountain is covered by dense vegetation.

The common difference between these samples and the other samples is that they were taken from stalactite grottos. Thus, stalactite grottos and other related karst topography might be present in their recharge zones as well. While the reason for the $\mathrm{NO}_{3 \mathrm{~atm}}^{-}$enrichment of these samples is still not clear, unique recharge routes (via holes or cracks on the surface, for instance) that lead to the direct addition of precipitation containing atmospheric nitrate to groundwater may 
occur in the recharge zones of the sources of these bottled waters.

Overall, higher $\mathrm{NO}_{3 \mathrm{~atm}}^{-}$concentrations were obtained for samples collected from sources recharged in rocky, arid and/or elevated areas having little vegetation and soils, while lower $\mathrm{NO}_{3 \mathrm{~atm}}^{-}$concentrations were obtained for those recharged in forested areas with high levels of vegetation (Fig. 5).

\subsection{Implications for nitrogen cycles through groundwater in general}

The water samples analyzed in this study were originally bottled for drinking; thus, most of their recharge zones were natural and remote, and they were not obtained from declining or damaged watersheds. As a result, the estimates of $\Delta^{17} \mathrm{O}$ values, $\mathrm{C}_{\mathrm{atm}} / \mathrm{C}_{\text {total }}$ ratios, and $\mathrm{C}_{\mathrm{atm}}$ in groundwater generated in the present study do not reflect global averages of nitrate in groundwater, but rather levels of water from aquifers recharged under healthy conditions.

As shown in Sect. 3.2, we estimated that only $3.1 \%$ of the total nitrate in the groundwater samples originates directly from the atmosphere; therefore, the remainder of nitrate is of remineralized origin. The average mixing ratio of $\mathrm{NO}_{3 \mathrm{~atm}}^{-}$is much smaller than that estimated for Rishiri Island $(7.4 \pm 2.6 \%)$. Moreover, this value was close to those in basic stream flows (3.1 to $7.7 \%)$ and soil extracts (1.9 to $11.4 \%$ ) observed in a semi-arid region in southern California (Michalski et al., 2004). These discrepancies are likely because previously studied fields deviated from the natural, background ecosystem. Because their hinterlands were either elevated mountains (Rishiri) or semi-arid (southern California) areas, the observed enrichment of the mixing ratios of $\mathrm{NO}_{3 \text { atm }}^{-}$were reasonable, while the present estimations reflect those of nitrate eluted from healthy and slightly declining forested watersheds.

By adding ${ }^{15} \mathrm{~N}$-labeled nitrogen $\left({ }^{15} \mathrm{NH}_{4}^{15} \mathrm{NO}_{3}\right.$ or $\mathrm{Na}^{15} \mathrm{NO}_{3}$ ) for a duration of 9 to 12 months to European coniferous forest ecosystems, Tietema et al. (1998) found that drainage losses of fixed nitrogen increased as a function of the fixed-nitrogen input. They estimated that drainage accounts for 2 to $35 \%$ of the total fixed-nitrogen input under a fixed-nitrogen input condition of less than $30 \mathrm{~kg} \mathrm{Nha}^{-1} \mathrm{yr}^{-1}$. The estimated direct drainage of $\mathrm{NO}_{3 \mathrm{~atm}}^{-}$ in this study corresponds to the lower region of the variation range estimated using ${ }^{15} \mathrm{~N}$ tracer. When using ${ }^{15} \mathrm{~N}$ tracer, direct drainage could be overestimated for the portion of secondary elution of ${ }^{15} \mathrm{NO}_{3}^{-}$that was once assimilated to organic nitrogen. Thus, the value generated in the present study is a more reliable estimate for the direct drainage of $\mathrm{NO}_{3 \mathrm{~atm}}^{-}$under low fixed-nitrogen input conditions of less than $30 \mathrm{~kg} \mathrm{Nha}^{-1} \mathrm{yr}^{-1}$.

\section{Summary and conclusions}

The average mixing ratio of $\mathrm{NO}_{3 \mathrm{~atm}}^{-}$to total nitrate in groundwater recharged in natural, background watersheds was estimated to be $3.1 \%$. Thus, we concluded that the majority of atmospheric nitrate had undergone biological processing before being exported from the surface ecosystem to the groundwater. Moreover, higher $\mathrm{NO}_{3 \mathrm{~atm}}^{-}$concentrations were obtained for those recharged in rocky, arid or elevated areas with little vegetation, while lower $\mathrm{NO}_{3 \mathrm{~atm}}^{-}$concentrations were obtained for those recharged in forested areas with high levels of vegetation. Uptake by plants and/or microbes in forested soils subsequent to deposition and the progress of denitrification within groundwater likely plays a significant role in the removal of $\mathrm{NO}_{3 \mathrm{~atm}}^{-}$(Fig. 5). The quantified $\mathrm{NO}_{3 \mathrm{~atm}}^{-}$output obtained in this study will be useful in future studies as a basic data set for evaluation of the amounts of $\mathrm{NO}_{3 \mathrm{~atm}}^{-}$eluted into groundwater from subaerial ecosystems in general, including the same watersheds under elevated $\mathrm{NO}_{3 \mathrm{~atm}}^{-}$input in the future.

Acknowledgements. We thank Soga Sato (Group Gendai Films Co., Ltd.) and Makoto Umeda (Tohoku Univ.) for providing bottled water samples, and Hiromi Hamada (Chiba Univ.) for valuable information regarding bottled drinking water. We are grateful to the members of the Geochemistry Group, Faculty of Science, Hokkaido University for their valuable support throughout this study. We thank Becky Alexander, Greg Michalski, and Carl Brenninkmeijer for their valuable comments on an earlier version of this manuscript. This work was supported by a Grant-in-Aid of Scientific Research from the Ministry of Education, Culture, Sports, Science, and Technology of Japan under grant numbers 20310003, 22651001, 22710001, 23241001, and 24651002 and the Global Environment Research Fund of the Ministry of the Environment of Japan (RFa-1102).

Edited by: X. Wang

\section{References}

Alexander, B., Hastings, M. G., Allman, D. J., Dachs, J., Thornton, J. A., and Kunasek, S. A.: Quantifying atmospheric nitrate formation pathways based on a global model of the oxygen isotopic composition $\left(\Delta^{17} \mathrm{O}\right)$ of atmospheric nitrate, Atmos. Chem. Phys., 9, 5043-5056, doi:10.5194/acp-9-5043-2009, 2009.

Böhlke, J. K., Mroczkowski, S. J., and Coplen, T. B.: Oxygen isotopes in nitrate: new reference materials for ${ }^{18} \mathrm{O}:{ }^{17} \mathrm{O}:{ }^{16} \mathrm{O}$ measurements and observations on nitrate-water equilibration, Rapid Commun. Mass Sp., 17, 1835-1846, 2003.

de Walle, F. B. and Sevenster, J.: Agriculture and the Environment: Minerals, Manure and Measures, Kluwer Academic Publishers, Dordrecht, 1998.

Dejwakh, N. R., Meixner, T., Michalski, G., and McIntosh, J.: Using ${ }^{17} \mathrm{O}$ to Investigate Nitrate Sources and Sinks in a SemiArid Groundwater System, Environ. Sci. Technol., 46, 745-751, 10.1021/es203450z, 2012. 
Duce, R. A., LaRoche, J., Altieri, K., Arrigo, K. R., Baker, A. R., Capone, D. G., Cornell, S., Dentener, F., Galloway, J., Ganeshram, R. S., Geider, R. J., Jickells, T., Kuypers, M. M., Langlois, R., Liss, P. S., Liu, S. M., Middelburg, J. J., Moore, C. M., Nickovic, S., Oschlies, A., Pedersen, T., Prospero, J., Schlitzer, R., Seitzinger, S., Sorensen, L. L., Uematsu, M., Ulloa, O., Voss, M., Ward, B., and Zamora, L.: Impacts of Atmospheric Anthropogenic Nitrogen on the Open Ocean, Science, 320, 893 897, 2008

Durka, W., Schulze, E.-D., Gebauer, G., and Voerkeliust, S.: Effects of forest decline on uptake and leaching of deposited nitrate determined from ${ }^{15} \mathrm{~N}$ and ${ }^{18} \mathrm{O}$ measurements, Nature, 372, 765767, 1994

EANET: Data Report 2007, Network center for EANET (Acid Deposition Monitoring Network in East Asia), Nigata, Japan, 229 pp., 2008.

Ewing, S. A., Michalski, G., Thiemens, M., Quinn, R. C., Macalady, J. L., Kohl, S., Wankel, S. D., Kendall, C., McKay, C. P., and Amundson, R.: Rainfall limit of the N cycle on Earth, Global Biogeochem. Cy., 21, GB3009, doi:10.1029/2006gb002838, 2007.

Fenn, M. E., Poth, M. A., Aber, J. D., Baron, J. S., Bormann, B. T., Johnson, D. W., Lemly, A. D., McNulty, S. G., Ryan, D. F., and Stottlemyer, R.: Nitrogen excess in north American ecosystems: Predisposing factors, ecosystem responses, and management strategies, Ecol. Appl., 8, 706-733, 1998.

Galloway, J. N., Townsend, A. R., Erisman, J. W., Bekunda, M., Cai, Z., Freney, J. R., Martinelli, L. A., Seitzinger, S. P., and Sutton, M. A.: Transformation of the Nitrogen Cycle: Recent Trends, Questions, and Potential Solutions, Science, 320, 889-892, 2008.

Grennfelt, P. and Hultberg, H.: Effects of nitrogen deposition on the acidification of terrestrial and aquatic ecosystems, Water Air Soil Poll., 30, 945-963, 1986.

Hirota, A., Tsunogai, U., Komatsu, D. D., and Nakagawa, F.: Simultaneous determination of $\delta^{15} \mathrm{~N}$ and $\delta^{18} \mathrm{O}$ of $\mathrm{N}_{2} \mathrm{O}$ and $\delta^{13} \mathrm{C}$ of $\mathrm{CH}_{4}$ in nanomolar quantities from a single water sample, Rapid Commun. Mass Sp., 24, 1085-1092, 2010.

Hiscock, K. M., Lloyd, J. W., and Lerner., D. N.: Review of natural and artificial denitrification of groundwater, Water Res., 25, 1099-1111, 1991.

Kaiser, J., Hastings, M. G., Houlton, B. Z., Röckmann, T., and Sigman, D. M.: Triple oxygen isotope analysis of nitrate using the denitrifier method and thermal decomposition of $\mathrm{N}_{2} \mathrm{O}$, Anal. Chem., 79, 599-607, 2007.

Kendall, C.: Tracing Nitrogen Sources and Cycling in Catchments, in: Isotope Tracers in Catchment Hydrology, edited by: Kendall, C. and McDonnell, J. J., Elsevier Science B.V., Amsterdam, 839 pp., 519-576, 1998.

Komatsu, D. D., Ishimura, T., Nakagawa, F., and Tsunogai, U.: Determination of the ${ }^{15} \mathrm{~N} /{ }^{14} \mathrm{~N},{ }^{17} \mathrm{O} /{ }^{16} \mathrm{O}$, and ${ }^{18} \mathrm{O} /{ }^{16} \mathrm{O}$ ratios of nitrous oxide by using continuous-flow isotope-ratio mass spectrometry, Rapid Commun. Mass Sp., 22, 1587-1596, 2008.

Kosaka, Y., Nagashima, S., Hasegawa, A., and Higashi, K.: Removal of nitrogen in wastewater by UV radiation and agent addition method, Bulletin of Tokyo Metropolitan Industrial Technology Research Institute, 5, 89-92, 2002.

Kunasek, S. A., Alexander, B., Steig, E. J., Hastings, M. G., Gleason, D. J., and Jarvis, J. C.: Measurements and modeling of $\Delta^{17} \mathrm{O}$ of nitrate in snowpits from Summit, Greenland, J. Geo- phys. Res., 113, D24302, doi:10.1029/2008jd010103, 2008.

Luz, B. and Barkan, E.: Assessment of Oceanic Productivity with the Triple-Isotope Composition of Dissolved Oxygen, Science, 288, 2028-2031, 2000.

Mauersberger, K., Erbache, B., Krankowsky, D., Gunther, J., and Nickel, R.: Ozone isotope enrichment: Isotopomer-specific rate coefficients, Science, 283, 370-372, 1999.

McIlvin, M. R. and Altabet, M. A.: Chemical conversion of nitrate and nitrite to nitrous oxide for nitrogen and oxygen isotope analysis in freshwater and seawater, Anal. Chem., 77, 5589-5595, 2005.

Michalski, G., Savarino, J., Böhlke, J. K., and Thiemens, M.: Determination of the total oxygen isotopic composition of nitrate and the calibration of a $\Delta^{17} \mathrm{O}$ nitrate reference material, Anal. Chem., 74, 4989-4993, doi:10.1021/Ac0256282, 2002.

Michalski, G., Scott, Z., Kabiling, M., and Thiemens, M. H.: First measurements and modeling of $\Delta^{17} \mathrm{O}$ in atmospheric nitrate, Geophys. Res. Lett., 30, doi:10.1029/2003GL017015, 2003.

Michalski, G., Meixner, T., Fenn, M., Hernandez, L., Sirulnik, A., Allen, E., and Thiemens, M.: Tracing Atmospheric Nitrate Deposition in a Complex Semiarid Ecosystem Using $\Delta^{17} \mathrm{O}$, Environ. Sci. Technol., 38, 2175-2181, 2004.

Miller, M. F.: Isotopic fractionation and the quantification of ${ }^{17} \mathrm{O}$ anomalies in the oxygen three-isotope system: an appraisal and geochemical significance, Geochim. Cosmochim. Ac., 66, 18811889, 2002.

Moore, K. B., Ekwurzel, B., Esser, B. K., Hudson, G. B., and Moran, J. E.: Sources of groundwater nitrate revealed using residence time and isotope methods, Appl. Geochem., 21, 10161029, 2006.

Morin, S., Savarino, J., Frey, M. M., Domine, F., Jacobi, H. W., Kaleschke, L., and Martins, J. M. F.: Comprehensive isotopic composition of atmospheric nitrate in the Atlantic Ocean boundary layer from 65 degrees S to 79 degrees N, J. Geophys. Res., 114, D05303, doi:10.1029/2008jd010696, 2009.

Murdoch, P. S. and Stoddard, J. L.: The Role of Nitrate in the Acidification of Streams in the Catskill Mountains of New York, Water Resour. Res., 28, 2707-2720, 1992.

Paerl, H. W.: Coastal eutrophication and harmful algal blooms: Importance of atmospheric deposition and groundwater as "new" nitrogen and other nutrient sources, Limnol. Oceanogr., 42, 1154-1165, 1997.

Savarino, J., Kaiser, J., Morin, S., Sigman, D. M., and Thiemens, M. H.: Nitrogen and oxygen isotopic constraints on the origin of atmospheric nitrate in coastal Antarctica, Atmos. Chem. Phys., 7, 1925-1945, doi:10.5194/acp-7-1925-2007, 2007.

Stensland, G. J., Whelpdale, D. M., and Oehlert, G.: Precipitation Chemistry, in: Acid Deposition: Long-Term Trends, edited by: Committee on Monitoring and Assessment of Trends in Acid Deposition, Environmental Studies Board, National Research Council, National Academy Press, Washington, DC, 128-199, 1986.

Tietema, A., Emmett, B. A., Gundersen, P., Kjonaas, O. J., and Koopmans, C. J.: The fate of N-15-labelled nitrogen deposition in coniferous ecosystems, Forest Ecol. Manag., 101, 19-27, 1998.

Tilman, D., Wedin, D., and Knops, J.: Productivity and sustainability influenced by biodiversity in grassland ecosystems, Nature, 379, 718-720, 1996. 
Tsunogai, U. and Wakita, H.: Precursory chemical changes in ground water: Kobe earthquake, Japan, Science, 269, 61-63, 1995.

Tsunogai, U. and Wakita, H.: Anomalous changes in ground water chemistry: Possible precursors of the Hyogo-ken Nanbu earthquake, Japan, J. Phys. Earth, 44, 381-390, 1996.

Tsunogai, U., Yoshida, N., Ishibashi, J., and Gamo, T.: Carbon isotopic distribution of methane in deep-sea hydrothermal plume, Myojin Knoll Caldera, Izu-Bonin arc: Implications for microbial methane oxidation in ocean and applications to heat flux estimation, Geochim. Cosmochim. Ac., 64, 2439-2452, 2000.

Tsunogai, U., Nakagawa, F., Komatsu, D. D., and Gamo, T.: Stable carbon and oxygen isotopic analysis of atmospheric carbon monoxide using continuous-flow isotope ratio MS by isotope monitoring of CO, Anal. Chem., 74, 5695-5700, 2002.

Tsunogai, U., Nakagawa, F., Gamo, T., and Ishibashi, J.: Stable isotopic compositions of methane and carbon monoxide in the Suiyo hydrothermal plume, Izu-Bonin arc: tracers for microbial consumption/production, Earth Planet. Sci. Lett., 237, 326-340, 2005.
Tsunogai, U., Kido, T., Hirota, A., Ohkubo, S. B., Komatsu, D. D., and Nakagawa, F.: Sensitive determinations of stable nitrogen isotopic composition of organic nitrogen through chemical conversion into $\mathrm{N}_{2} \mathrm{O}$, Rapid Commun. Mass Sp., 22, 345-354, 2008.

Tsunogai, U., Komatsu, D. D., Daita, S., Kazemi, G. A., Nakagawa, F., Noguchi, I., and Zhang, J.: Tracing the fate of atmospheric nitrate deposited onto a forest ecosystem in Eastern Asia using $\Delta^{17}$ O, Atmos. Chem. Phys., 10, 1809-1820, doi:10.5194/acp10-1809-2010, 2010.

Tsunogai, U., Daita, S., Komatsu, D. D., Nakagawa, F., and Tanaka, A.: Quantifying nitrate dynamics in an oligotrophic lake using $\Delta^{17} \mathrm{O}$, Biogeosciences, 8, 687-702, doi:10.5194/bg-8-687-2011, 2011.

Williams, M. W., Baron, J. S., Caine, N., Sommerfeld, R., and Sanford, R.: Nitrogen Saturation in the Rocky Mountains, Environ. Sci. Technol., 30, 640-646, 1996. 